\title{
Relevant and selective activity of Pancratium illyricum L. against Candida albicans clinical isolates: a combined effect on yeast growth and virulence
}

Francesca Bonvicini ${ }^{1}$, Fabiana Antognoni ${ }^{2 *}$, Carmelina lannello ${ }^{3}$, Andrea Maxia ${ }^{4}$, Ferruccio Poli ${ }^{3}$ and Giovanna Angela Gentilomi ${ }^{1}$

\begin{abstract}
Background: Alkaloids present in plants of the Amaryllidaceae family are secondary metabolites of high biological interest, possessing a wide range of pharmacological activities. In the search for new plant-derived compounds with antimicrobial activities, two alkaloid extracts obtained from bulbs and leaves of Pancratium illyricum L., a plant of the Amarillydaceae family, were tested for their effect on bacterial and yeast growth.

Methods: The broth microdilution susceptibility test was applied to study the effect of plant extracts on the growth of reference bacterial strains and Candida albicans reference and clinical isolates strains. Extracts obtained from the different parts of the plant were tested and compared with the pure components identified in the extracts. Since matrix metalloproteinase enzymes play a role in the dissemination process of Candida albicans, the effect of the bulb extract and pure alkaloids on in vitro collagenase activity was tested. Cell viability test was carried out on human embryo lung fibroblasts (HEL 299).

Results: Whilst both extracts did not show any inhibitory activity against neither Gram positive nor Gram negative bacteria, a strong antifungal activity was detected, in particular for the bulb extract. All clinical isolates were susceptible to the growth inhibitory activity of the bulb extract, with endpoint $I C_{50}$ values ranging from 1.22 to $78 \mathrm{\mu g} / \mathrm{mL}$. The pure alkaloids lycorine and vittatine, identified as components of the extract, were also assayed for their capacity of inhibiting the yeast growth, and lycorine turned very active, with endpoint $I C_{50}$ values ranging from 0.89 to $28.5 \mu \mathrm{g} / \mathrm{mL}$. A potent inhibition of the in vitro collagenase activity was found in the presence of the bulb extract, and this effect was much higher than that exerted by the pure alkaloids. Viability of cell lines tested was not affected by the extract.

Conclusions: Taken together, results suggest that the extract of Pancratium illyricum may act as antifungal agent both directly on the yeast growth and by altering the tissue invasion process.
\end{abstract}

Keywords: Candida albicans clinical isolates, Plant-derived compounds, Antifungal activity, Collagenase activity, Pancratium illyricum L

\footnotetext{
*Correspondence: fabiana.antognoni@unibo.it

${ }^{2}$ Department for Life Quality Studies, University of Bologna, Corso Augusto, 237, 47921 Rimini, Italy

Full list of author information is available at the end of the article
} 


\section{Background}

Candida albicans is an important pathogen of humans characterized by a high versatility. The yeast is a commensal in several anatomically distinct sites and, under an extensive variety of predisposing factors (ranging from specific immune defects to mucosal or cutaneous barrier disruption, ageing, diabetes, AIDS), it can invade tissues leading to a wide spectrum of clinical symptoms.

Among the early events in the pathogenesis of candidiasis there are the adhesion of the yeast cells to host cells, the yeast-hyphal transition, with changes in antigen expression and tissue affinities, and the direct persorption into the submucosa [1]. Subsequently, for the dissemination, $C$. albicans can affect host matrix metalloproteinases (MMPs) expression, mainly MMP-9, leading to tissue degradation and inflammatory processes [2].

MMPs are a family of secreted or cell surface-associated proteolytic enzymes targeting almost all extracellular matrix (ECM) components and basement membrane proteins [3]. MMPs have been classified according to their substrate specificities and are often referred to as collagenases, gelatinases, stromelysins, matrilysins, and membrane-type MMPs. The catalytic domain of all MMPs contains a zincbinding motif, an additional structural zinc ion, and 2-3 calcium ions, which are required for the stability and the expression of enzyme activity [4]. To date, many extracts or compounds from plant origin have been studied as possible inhibitors of some MMPs as the modulation of their expression has been implicated in inflammatory disorders, cancer invasion, metastasis, and microbial infections $[5,6]$.

Concerning antifungal therapy, candidiasis are widely treated with triazole drugs (fluconazole, voriconazole, itraconazole, and posaconazole) that inhibit the biosynthesis of the ergosterol, the major sterol in the fungal plasma membrane. However, their extensive use has raised concern about resistant infections that negatively impact the clinical outcome mainly for high risk patients and those with persistent mycoses [7].

In the search for naturally derived compounds with promising antimicrobial activities, a particular focus was recently given to the alkaloids produced by plants of the Amaryllidaceae family. Indeed, the Amaryllidaceae alkaloids are secondary metabolites of high biological interest, possessing, among others, antimicrobial, antitumoral and acetylcholinesterase inhibitory activities [8-10]. Several species of Crinum have already been proven for their antibacterial and antifungal activities. For instance, the alkaloid crinamine isolated from bulbs of $C$. jagus showed strong inhibitory activity against Staphylococcus aureus [11], and in vitro activity against C. albicans was demonstrated for C. macowanii extract [12]. Alkaloids present in $C$. angustum Steud [13] and C. purpurascens [14] were also reported to possess antibacterial and antifungal activities.
In the present study, a set of 30 C. albicans clinical isolates was tested to explore the antifungal activity of an alkaloid extract of Pancratium illyricum L., a species endemic to Sardinia, Corsica and the Tuscan archipelago [15]; the in vitro anti-collagenase activity and the mechanism of action of $P$. illyricum extract towards the collagenase enzyme were also investigated.

This work was aimed at finding new antifungal agents having anti-collagenase activity, which may also affect the yeast virulence, in a combined effect with growth inhibition.

\section{Methods}

\section{Clinical isolates}

The study included 30 C. albicans clinical isolates recovered from urine samples, collected at S. Orsola-Malpighi Hospital, Bologna (Italy). All isolates were cultured on CHROMagar Orientation Medium (Becton Dickinson, Heidelberg, Germany), then species identification was carried out by standard procedures, including colony morphology on chromogenic agar (CHROMagar Candida Medium, Becton Dickinson), and confirmed by MALDI Biotyper System using matrix-assisted laser desorption ionization-time of flight mass spectrometry (MALDITOF MS, Bruker Daltonik, GmbH, Germany) [16].

\section{Plant material}

Pancratium illyricum L. was collected during the flowering period (May 2011) in the South of Sardinia (Punta San Michele, CA, Italy), and identified by Professor Mauro Ballero (University of Cagliari, Italy). A voucher specimen (CAG 1365) has been deposited in the Institute of Botany, University of Cagliari.

\section{Extraction and isolation of pure alkaloids}

An extract enriched in alkaloids was prepared from bulbs and leaves separately. Fresh plant material (298 g and $168 \mathrm{~g}$, respectively) was crushed in small pieces and exhaustively extracted with $\mathrm{MeOH}$ at room temperature for $72 \mathrm{~h}$. The extracts were evaporated under reduced pressure to yield $15.85 \mathrm{~g}$ and $10.17 \mathrm{~g}$ for bulbs and leaves, respectively. These crude extracts were acidified by dissolving in $100 \mathrm{~mL} \mathrm{H}_{2} \mathrm{SO}_{4}$ $1 \%(\mathrm{v} / \mathrm{v})$ and neutral material was removed with $n$-hexane $(6 \times 100 \mathrm{~mL})$ and chloroform $\left(\mathrm{CHCl}_{3}, 4 \times 100 \mathrm{~mL}\right)$. The acidified solution was then basified with $25 \% \mathrm{NH}_{4} \mathrm{OH}$ up to $\mathrm{pH}$ 9-10 and extracted with $\mathrm{CHCl}_{3}(4 \times 100 \mathrm{~mL})$ to give the $\mathrm{CHCl}_{3}$ extract containing alkaloids $(130 \mathrm{mg}$ for bulbs and $120 \mathrm{mg}$ for leaves). Both extracts were dried with anhydrous $\mathrm{Na}_{2} \mathrm{SO}_{4}$, filtered and completely dried under reduced pressure. The extract yields, on a fresh weight basis, were $0.05 \%$ for bulbs and $0.07 \%$ for leaves. The $\mathrm{CHCl}_{3}$ bulb extract was then subjected to vacuum liquid chromatography (VLC) [13] using a silica gel $60 \AA(6-35 \mu \mathrm{m})$ column (1 cm diameter and $4 \mathrm{~cm}$ height). Alkaloids were eluted using $n$-hexane 
gradually enriched with ethylacetate (EtOAc), then gradually enriched with $\mathrm{CHCl}_{3}$ and finally with a mixture of EtOAc and $\mathrm{CHCl}_{3}$ gradually enriched with $\mathrm{MeOH}$. Fractions of $10 \mathrm{~mL}$ were collected (200 in total), monitored by TLC (Dragendorff's reagent, UV $254 \mathrm{~nm}$ ) and combined according to their profiles. Nine main fractions were obtained and subjected to preparative TLC $(20 \mathrm{~cm} \times 20 \mathrm{~cm} \times 0.25 \mathrm{~mm}$, silica gel 60 F254). Crystals of lycorine and vittatine soluble compounds were obtained in major quantities from fractions 128-133 (eluted from VLC with $n$-Hexane-EtOAc$\mathrm{CHCl}_{3}, 20: 60: 20$ to $\left.15: 60: 25\right)$. Crystals of lycorine (20 mg) were collected as needles by separating from the solvent and then subjected to GC-MS analysis to confirm the alkaloid identity. Vittatine $(7 \mathrm{mg}$ ) was obtained through preparative TLC from collected fractions (EtOAc- $\mathrm{CHCl}_{3}$ $\mathrm{CH}_{3} \mathrm{OH}$ 3:1:1 + 25\% ammonia).

EIMS were obtained on a GC-MS Hewlett-Packard $6890+$ MSD 5975 operating in EI mode at $70 \mathrm{eV}$. A HP-5 MS column $(30 \mathrm{~m} \times 0.25 \mathrm{~mm} \times 0.25 \mu \mathrm{m})$ was used. The temperature program was: $100-180^{\circ} \mathrm{C}$ at $15^{\circ} \mathrm{C}$ min- 1 , $1 \mathrm{~min}$ hold at $180^{\circ} \mathrm{C}, 180-300^{\circ} \mathrm{C}$ at $5^{\circ} \mathrm{C}$ min -1 and $1 \mathrm{~min}$ hold at $300^{\circ} \mathrm{C}$. Injector temperature was $280^{\circ} \mathrm{C}$. The flow rate of the carrier gas (helium) was $0.8 \mathrm{~mL}$ min-1.

The compounds of the final $\mathrm{CHCl}_{3}$ extracts of bulbs and leaves, and the pure compounds lycorine and vittatine, were identified as TMS with the help of the NIST 05 database (NIST Mass Spectral Database, PC-Version 5.0, 2005, National Institute of Standardisation and Technology, Gaithersburg, MD, USA), and other plant-specific databases: the Golm Metabolome Database (http://csbdb. mpimp-golm.mpg.de/csbdb/gmd/home/gmd_sm.html), on the basis of matching mass spectra and Kovats retention indexes (RI). The measured mass spectra were deconvoluted by the Automated Mass Spectral Deconvolution and Identification System (AMDIS 2.64, NIST Gaithersburg, MD) before comparison with the databases. RI values of the compounds were measured with standard n-hydrocarbon calibration mixture (C9-C36; Restek, Bellefonte, PA, USA, catalogue no. 31614, supplied by Teknokroma, Spain) using AMDIS 2.64 software. Additional files 1, 2, 3, 4, 5, 6 and 7 show the GC-MS profile of the bulb extract and pure compounds identified.

\section{Susceptibility testing}

Preliminary experiments were performed on standard American Type Culture Collection (ATCC) strains: Staphylococcus aureus ATCC 25923, Staphylococcus epidermidis ATCC 12228, Escherichia coli ATCC 25922, Klebsiella pneumoniae ATCC 9591, and on C. albicans ATCC 10231.

Bacteria strains were assayed with the alkaloid extracts of P. illyricum, from bulbs and leaves (12 dilutions; range 0.156 to $312 \mu \mathrm{g} / \mathrm{mL}$ ), and gentamicin (Sigma-Aldrich,
Saint Louis, USA) as reference drug control, by means of a previously described broth microdilution protocol [13].

All yeast strains were assayed with the alkaloid extracts of $P$. illyricum, from bulbs and leaves, (12 dilutions; range range 0.156 to $312 \mu \mathrm{g} / \mathrm{mL}$ ), the pure compounds lycorine and vittatine (12 dilutions; range 0.03 to $114 \mu \mathrm{g} / \mathrm{mL}$ and 0.05 to $225 \mu \mathrm{g} / \mathrm{mL}$, respectively) and amphotericin B (12 dilutions; range 0.002 to $5 \mu \mathrm{g} / \mathrm{mL}$ ). Amphotericin B was supplied from Sigma (Sigma-Aldrich, Saint Louis, USA).

Inocula of all Candida isolates and two-fold microdilution broth method were performed according to the European Committee on Antimicrobial Susceptibility Testing (EUCAST) guidelines [17]. Briefly, the inoculum was prepared by suspending a maximum of 5 distinct colonies in $5 \mathrm{~mL}$ of sterile $0.9 \%$ saline solution, then density was adjusted at 0.5 McFarland by measuring the absorbance (DU-530 UV-vis Spectrophotometer, Beckman Coulter, Inc., CA, USA). Finally, a working suspension was prepared from a 1:10 dilution of the standardized suspension in RPMI-1640 medium (Gibco ${ }^{\circ}$, Thermo Fisher Scientific Inc., Waltham, USA), containing glucose $2 \%$, $0.3 \%$ levoglutamine, $0.165 \mathrm{M}$ 3-(N-morpholino)-propanesulfonic acid (MOPS), pH 7.0, to yield $1-5 \times 10^{5} \mathrm{CFU} / \mathrm{mL}$.

Each well of a 96-well microplate was inoculated with $100 \mu \mathrm{L}$ of the yeast suspension and with $100 \mu \mathrm{L}$ of the testing drugs, serially two-fold diluted in RPMI-1640 medium. Growth control wells containing $100 \mu \mathrm{L}$ of sterile drug-free medium and $100 \mu \mathrm{L}$ of the same inoculum were also prepared, as well as negative control wells. Finally, solvent controls were prepared by serially diluting DMSO (12 dilutions; starting from 3.12\%) to measure its interfering effect on yeast growth. Each strain and all controls were tested in triplicate. The microdilution plates were incubated at $37^{\circ} \mathrm{C}$ for $24 \mathrm{~h}$, without agitation, and subsequently the absorbance at $530 \mathrm{~nm}$ was measured by the Multiskan Ascent microplate reader (Thermo Fisher Scientific Inc., Waltham, USA). The growth inhibition of the yeast cells was calculated and expressed as MIC (minimum inhibitory concentration) and $\mathrm{IC}_{50}$ (concentration required for a growth reduction of the $50 \%$ ).

The minimal fungicidal concentrations (MFCs) were determined by subculturing $50 \mu \mathrm{L}$ of supernatants from the wells where no growth was observed in broth microdilution plates, previously described. The samples were cultured on Sabouraud agar plates (Becton Dickinson, Heidelberg, Germany) and incubated at $37^{\circ} \mathrm{C}$ for $24 \mathrm{~h}$. The MFC was the lowest drugs concentration that showed either no growth or fewer than 3 colonies to obtain approximately 99 to $99.5 \%$ killing activity [18]. The MFC was determined from three independent experiments.

\section{Anti-collagenase assay}

The bulbs extract of $P$. illyricum and pure compounds, lycorine and vittatine, were tested for their capacity of 
inhibiting in vitro collagenase activity. The assay employed was based on a spectrophotometric method reported in the literature [19], slightly modified for a 96-well microplate, using Clostridium hystolyticum collagenase (EC.3.4.23.3) and FALGPA (N-[3-(2-Furyl)acryloyl]-Leu-Gly-Pro-Ala) as substrate. Enzyme was dissolved in $50 \mathrm{mM}$ Tricine buffer (containing $10 \mathrm{mM} \mathrm{CaCl}_{2}$ and $400 \mathrm{mM} \mathrm{NaCl}$ ), $\mathrm{pH} 7.5$, to give 0.8 units $/ \mathrm{mL}$ (according to the supplier's activity data); a $2 \mathrm{mM}$ solution of substrate FALGPA was prepared in the same buffer. Twenty-five $\mu \mathrm{L}$ buffer, $25 \mu \mathrm{L} \mathrm{H}_{2} \mathrm{O}$ or inhibitor, and $25 \mu \mathrm{L}$ enzyme were loaded into each well of the microtplate, and after 15 min preincubation, $50 \mu \mathrm{L}$ of substrate were added. Absorbance was measured at $340 \mathrm{~nm}$ immediately and at 2-min intervals for $20 \mathrm{~min}$. Enzyme activity was estimated by following the decrease in absorbance during the time interval due to substrate hydrolysis. Epigallocatechin gallate (EGCG) was used as positive control. Four substrate concentrations in the range $0.5 \mathrm{mM}-2.5 \mathrm{mM}$ were assayed to elucidate the mechanism of inhibition.

\section{Cell viability testing}

Cytotoxic effects of the bulbs extract of P. illyricum were evaluated against the human embryo lung fibroblasts (HEL 299) by using the commercially available alamarBlue Assay (Life Technologies, Thermo Fisher Scientific Inc., Waltham, USA). Cells were grown in EMEM (Eagle's Minimum Essential Medium, Gibco ${ }^{\oplus}$, Thermo Fisher Scientific Inc., Waltham, USA) supplemented with $10 \%$ fetal calf serum (Lonza, VWR International, Radnor, USA), $10 \mathrm{U}$ of penicillin and $50 \mu \mathrm{g} / \mathrm{mL}$ streptomycin at $37^{\circ} \mathrm{C}$ and $5 \% \mathrm{CO}_{2}$. For each set of experiments, cells were seeded at the density of $10^{4}$ cells/well in a 96-well culture microplate and incubated with $100 \mu \mathrm{L}$ of the extract at concentrations ranging from 0.016 to $312 \mu \mathrm{g} / \mathrm{mL}$ diluted in complete medium. In addition, cells were tested with dilutions of amphotericin B (0.002 to $5 \mu \mathrm{g} / \mathrm{mL})$ and DMSO (0.0015 to $3.12 \%)$. Positive controls containing cells in regular medium were also included.

Cells were grown for $24 \mathrm{~h}$ at $37^{\circ} \mathrm{C}$, then the medium was discarded, cells were replenished with $100 \mu \mathrm{L}$ of new complete medium and $10 \mu \mathrm{L}$ of the ready-to-use alamarBlue reagent were added to wells. The ingredient, resazurin (no-fluorescent form), is a cell permeable compound that, upon entering cells, is reduced to resorufin (fluorescent form) as cellular innate metabolic activity results. Reduction of alamarBlue was quantitatively evaluated following a 4 and $24 \mathrm{~h}$ of incubation by fluorescence measurement at the Varioskan Flash Multimode Reader (Thermo Fisher Scientific Inc., Waltham, USA) using a fluorescence excitation peak at $570 \mathrm{~nm}$ and emission peak at $585 \mathrm{~nm}$. All determinations were confirmed by replication of three experiments.

\section{Data analysis}

The antifungal activities of the P. illyricum, bulbs and leaves, pure compounds (lycoyine and vittatine), and amphotericin $\mathrm{B}$, as reference control, were evaluated by the determination of the MIC, corresponding to the lowest concentration giving rise to an inhibition of yeast growth $\geq 90 \%$ of that of the solvent DMSO or drug-free controls. Moreover, two $\mathrm{IC}_{50}$ values were calculated for each tested reagent: an endpoint $\mathrm{IC}_{50}$, defined as the lowest drug concentration leading to a yeast growth reduction of the $50 \%$, and an experimental $\mathrm{IC}_{50}$, obtained by the interpolation of growth data on dose-response curves (Figure 1). These curves were determined by plotting the percentages of growth inhibition, relative to the solvent or to the positive growth controls, as function of the 12 tested concentrations (in logarithm scale). Statistical analysis were carried out by nonlinear regression method using GraphPad Prism version 5.00 for Windows (GraphPad Software, San Diego California, USA).

In the anti-collagenase assay the percentage inhibition of enzyme activity was calculated by the following formula: \%inhibition $=[1-(\Delta \mathrm{Abs} / \mathrm{min}$ sample $/ \Delta \mathrm{Abs} / \mathrm{min}$ negative control $) \times 100]$

$\mathrm{IC}_{50}$ (concentration necessary for $50 \%$ inhibition of enzyme activity) was calculated by constructing a linear regression curve. A Lineweaver-Burk (L-B) plot was built to calculate the kinetic parameters $\left(K_{m}\right.$ expressed in $\mathrm{mM}$ and $\mathrm{V}_{\max }$ in $\mathrm{nmol} / \mathrm{s}$ ) of the enzymatic reaction without and with $P$. illyricum bulbs extract, at the $\mathrm{IC}_{50}$ concentration.

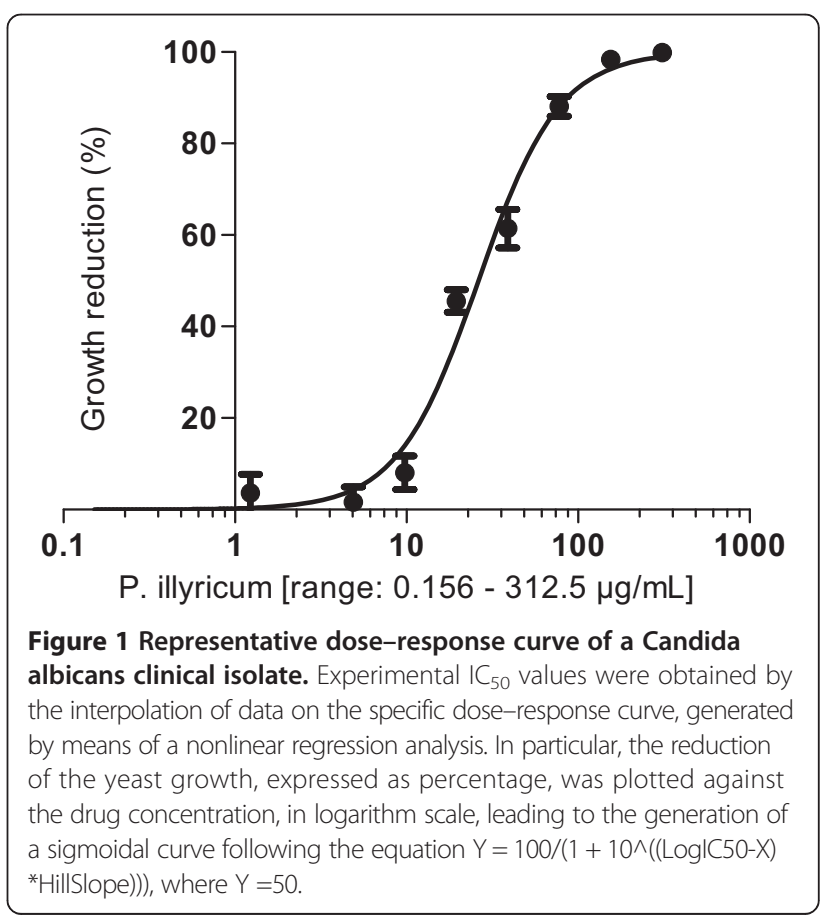


Cell viability was assessed on HEL 299 cell line after $4 \mathrm{~h}$ and $24 \mathrm{~h}$ of incubation with the bulbs extract of $P$. illyricum and amphotericin $B$. The reduction of the non-fluorescent compound into a fluorescent form of resorufin from living cells was quantitatively measured and expressed as percentage of growth, relative to solvent or positive HEL 299 controls. A growth inhibition $\geq 20 \%$ was considered affecting cell proliferation [20].

\section{Results}

\section{$P$. illyricum extracts and pure compounds}

Bulb and leaf extracts from P. illyricum were found to possess a slightly different alkaloid profile, as reported in Iannello et al. [13]. In particular, besides the presence of common alkaloids found in both organs of the plant, some exclusive alkaloids only present in leaves were reported. Lycorine and vittatine turned to be present in both plant organs.

\section{Antifungal activity}

In a preliminary set of experiments, extracts from both bulbs and leaves were assayed with conventional broth microdilution susceptibility testings on reference bacteria strains (Staphylococcus aureus ATCC 25923, Staphylococcus epidermidis ATCC 12228, Escherichia coli ATCC 25922, and Klebsiella pneumoniae ATCC 9591) and on C. albicans ATCC 10231. Data obtained demonstrated that P. illyricum extracts were completely uneffective against both Grampositive and Gram-negative bacteria, while turned rather active against $C$. albicans. Between the bulb and the leaf extracts, the former showed a higher inhibitory effect on the yeast growth compared to the latter $\left(\mathrm{IC}_{50}\right.$ endpoint 39 and $78 \mu \mathrm{g} / \mathrm{mL}$, respectively), and, as a consequence, it was subjected to further investigations. Its effect was compared to that of pure alkaloids lycorine and vittatine, and with amphotericin B. Data on their activities are summarized in Table 1.

All C. albicans clinical isolates proved to be susceptible to the bulbs extract of $P$. illyricum, with endpoint $\mathrm{IC}_{50}$

Table 1 Results of the antifungal activities of the bulbs extract and its pure alkaloids

\begin{tabular}{|c|c|c|c|}
\hline & \multicolumn{3}{|c|}{ Antifungal activities } \\
\hline & $\begin{array}{c}\text { experimental } I C_{50} \\
(\mu \mathrm{g} / \mathrm{mL})\end{array}$ & $\begin{array}{l}\text { endpoint IC } C_{50} \\
(\mu \mathrm{g} / \mathrm{mL})\end{array}$ & $\begin{array}{c}\mathrm{MIC} \\
(\mu \mathrm{g} / \mathrm{mL})\end{array}$ \\
\hline P. illyricum bulbs & $0.65-47$ & $1.22-78$ & $19.5-156$ \\
\hline Lycorine & $0.46-16.95$ & $0.89-28.50$ & $3.56-57$ \\
\hline Vittatine & - & - & - \\
\hline Amphotericin B & $0.02-0.23$ & $0.039-0.625$ & $0.078-1.25$ \\
\hline
\end{tabular}

values and experimental $\mathrm{IC}_{50}$ values ranging from 1.22 to 78 , and from 0.65 to $47 \mu \mathrm{g} / \mathrm{mL}$, respectively. Moreover, the frequency distribution of the endpoint $\mathrm{IC}_{50}$ was normally distributed $\left(R^{2}=0.932\right)$ with a mean value of $48.94 \mu \mathrm{g} / \mathrm{mL}$ and a $95 \%$ confident interval within 44.06 and $53.82 \mu \mathrm{g} /$ $\mathrm{mL}$ (Figure 2). These values, significantly lower than $100 \mu \mathrm{g} / \mathrm{mL}$, perfectly comply with the criteria suggested by Cos et al. [21], and demonstrate that bulbs possess a relevant and selective activity against $C$. albicans strains.

The pure compounds, lycorine and vittatine, were assayed against the yeast isolates in order to identify the main active components in the alkaloid extract. C. albicans growths were not inhibited by vittatine at the tested concentrations $(0.05-225 \mu \mathrm{g} / \mathrm{mL})$, while lycorine potently reduced yeast growth with endpoint $\mathrm{IC}_{50}$ values ranging from 0.89 to $28.50 \mu \mathrm{g} / \mathrm{mL}(3.10-99.19 \mu \mathrm{M})$. Experimental $\mathrm{IC}_{50}$ values for lycorine and bulbs extract were arranged in a XY plot (Figure 3) displaying a linear correlation $\left(R^{2}=0.949\right)$; this result suggests that this compound is likely to contribute to the antifungal activity of the total extract of $P$. illyricum.

After $\mathrm{IC}_{50}$ and $\mathrm{MIC}$ determinations, the MFCs were measured by subculturing the supernatants from the susceptibility testings. At the tested concentrations, both $P$. illyricum extract and lycorine did not act as fungicidal agents.

All C. albicans isolates were susceptible to the reference amphotericin $\mathrm{B}$ drug with endpoint $\mathrm{IC}_{50}$ values and MICs ranging from 0.039 to $0.625 \mu \mathrm{g} / \mathrm{mL}$ and $0.078-1.25 \mu \mathrm{g} / \mathrm{mL}$, respectively; MFCs were equal to MICs or two-folds higher according to the behavior of a fungicidal agent [18].

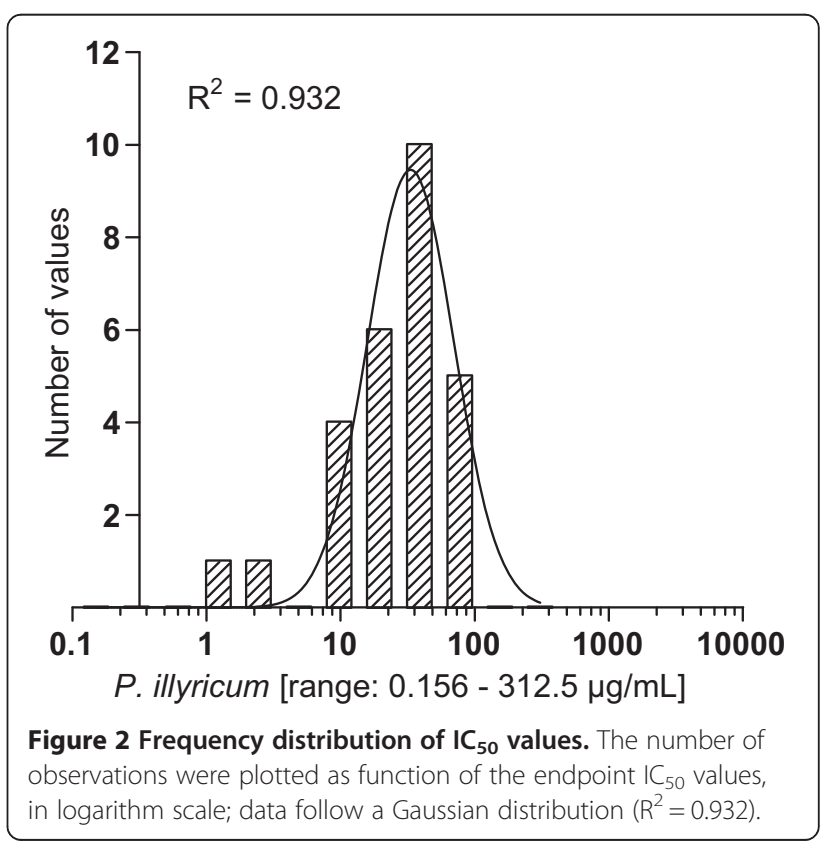




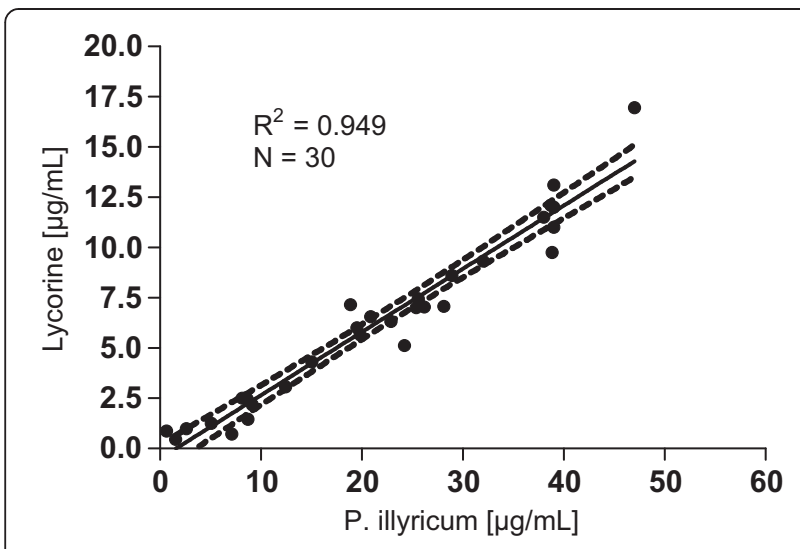

Figure 3 Analysis of correlation between experimental IC $C_{50}$ values obtained for P. illyricum and lycorine on Candida albicans clinical isolates. A scatter plot was generated with the experimental $I C_{50}$ values obtained for $P$. illyricum bulbs and lycorine showing a positive linear pattern $\left(R^{2}=0.949\right)$. Dotted lines indicate the $95 \%$ confident interval.

\section{Anti-collagenase activity}

$P$. illyricum bulb extract and pure compounds, lycorine and vittatine, were tested for their inhibiting effect on in vitro collagenase activity at an initial concentration of $200 \mu \mathrm{g} / \mathrm{mL}$; this is the maximum concentration that can be tested with this extract without having any spectrophotometrical interference [19]. The highest anticollagenase activity was displayed by the whole extract, reaching a 99.61\% inhibitory activity, while the pure compounds, at the same concentration, showed a much lower inhibiting effect, being below 30\%. The bulbs extract of $P$. illyricum was further investigated to determine $\mathrm{IC}_{50}$ value, which turned out to be about six times higher compared to EGCG, the reference compound for this assay (Table 2). The mechanism of action of the bulb extract towards inhibition of the collagenase enzyme has been evaluated. To this purpose, the enzyme kinetics in the absence and presence of the extract was followed, and a Lineweaver-Burk plot was built, as shown in Figure 4.

Variation of Vmax and $K_{M}$ values in the presence of bulb extract compared to the enzyme without inhibitor suggests that the inhibition is of reversible- and uncompetitive-type. Indeed, both values turned out to be reduced by about $50 \%$ in the presence of the extract (Table 3), as a consequence of the interaction with the enzyme-substrate complex.

\section{Cell viability testing}

The analysis of cellular health of HEL 299 cell line after $24 \mathrm{~h}$ of incubation with the alkaloid extract of P. illyricum

Table 2 IC $_{50}$ values of $P$. illyricum bulb extract, and of the reference compound epigallocatechin gallate

\begin{tabular}{ccc}
\hline & $\mathbf{I C}_{\mathbf{5 0}}(\boldsymbol{\mu} \mathbf{g} / \mathbf{m L})$ & $\mathbf{I C}_{\mathbf{5 0}}(\boldsymbol{\mu} \mathbf{M})$ \\
\hline P. illyricum bulbs & $25.00 \pm 0.1$ & - \\
EGCG & $4.33 \pm 0.02$ & $9.45 \pm 0.5$ \\
\hline
\end{tabular}

bulbs was carried out by evaluating the natural reducing power of living cells. The conversion of the substrate resazurin in resorufin by metabolically active cells was quantitatively measured at 4 and $24 \mathrm{~h}$ after adding the alamarBlue reagent. Both data demonstrated that the extract of $P$. illyricum did not interfere with the regular cell proliferation at the tested concentrations (data not shown).

\section{Discussion and conclusions}

The present study was aimed at evaluating the potential of the alkaloid extract of $P$. illyricum bulbs as source for novel antimicrobial agent. While no inhibitory activity was found against bacteria, a good antifungal activity was observed on C. albicans clinical isolates. In vitro susceptibility assays were performed against 30 yeast strains concurrently with the lycorine and vittatine, alkaloids mainly present in the bulb, isolated and purified from the plant. The $\mathrm{IC}_{50}$ values for the bulbs, ranging from 0.65 to $47 \mu \mathrm{g} / \mathrm{mL}$, demonstrate the relevant antifungal activity of $P$. illyricum, since they perfectly meet the stringent criteria for "activity" established by Cos et al. [21]. The analysis of the pure compounds allowed to identify the lycorine as the major active component on the bulbs extract. Indeed, vittatine was completely uneffective, while lycorine has a potent inhibitory effect on fungal growth, with a mean experimental $\mathrm{IC}_{50}$ value of $22.03 \mu \mathrm{M}$, again complying with the threshold $(<25 \mu \mathrm{M})$ suggested for pure compounds [21]. In addition, the experimental $\mathrm{IC}_{50}$ values significantly correlate with those of the bulbs extract, corroborating that lycorine mostly contributes to the biological activities observed against C. albicans clinical isolates. Our results are in agreement with those obtained by other researchers [8] indicating that lycorine is not active on bacteria while is a potent inhibitor of C. albicans growth. The inactivity of lycorine on some bacterial strains can be explained by the fact that bacteria, as Staphylococcus aureus, are able to transform lycorine in its inactive metabolite 2-O-demethylungiminorine, instead of the active ungeremine [22]. A recent study carried out on pathogenic crop fungi suggests that lycorine may act by damaging cell membranes, leading to the exosmosis of intracellular materials [23]. Consequently, substrate absorption and cell metabolism are strongly affected.

In addition to the antifungal properties, the present study investigated the activity of $P$. illyricum against collagenase, enzyme belonging to the MMPs family [3]. Of note, $C$. albicans holds a $95 \mathrm{kDa}$ metallopeptidase in the cell wall and produces extracellular proteinases, assisting the pathogen in the infectious process [24-26]. The identification of compounds with anti-metallopeptidase activity, thus targeting yeast virulence, represents a crucial step in the candidiasis drug development. Interestingly, some antibiotics, such as tetracycline, are known for their 


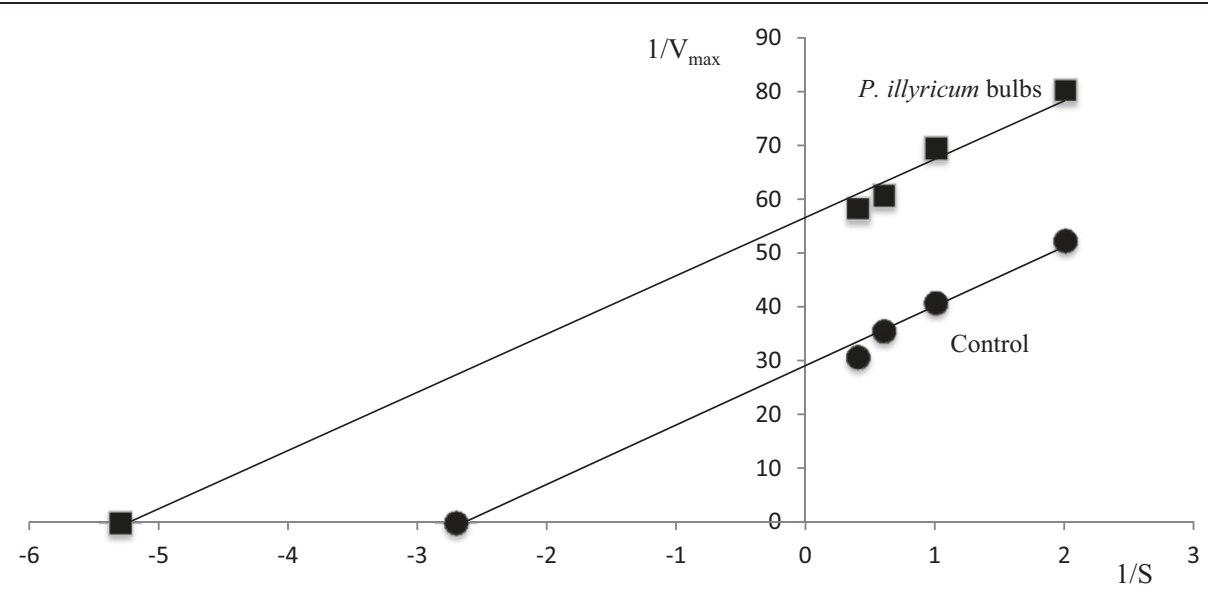

Figure 4 Lineaweaver-Burk plot of Clostridium collagenase and FALGPA without $(\bullet)$ and with ( $\bullet$ ) P. illyricum bulb extract. Enzyme assay was performed with a FALGPA concentration range of $0.5-2.5 \mathrm{mM}$.

ability to inhibit the activity of some collagenases [27] than for their direct action towards microorganisms. The bulbs extract of $P$. illyricum markedly inhibited the collagenase enzyme (99.61\%), with an $\mathrm{IC}_{50}$ value directly comparable with that of the reference standard (EGCG) while the pure compounds displayed a moderate inhibitory activity (30\%), at the same enzyme concentration. In this regards, it is possible to speculate that the extract is more active than the purified compounds because, in the former, there is a synergic action of several compounds [28], and the anti-collagenase activity is not due solely to the lycorine, differently from what observed for the antifungal properties. The analysis of the mechanism of inhibition of bulbs extract of $P$. illyricum towards the collagenase enzyme reveals that the inhibition is of reversible- and uncompetitive-type, thus suggesting that an interaction with the enzyme-substrate complex occurs, bringing to a higher affinity of the enzyme towards the substrate. Thus, taken together, results obtained in the present study suggest that alkaloid extract of $P$. illyricum is a very attractive and auspicious candidate for antifungal drug development since it combines two modes of action: as conventional antimicrobial agents, the extract selectively interferes with yeast cell viability by inhibiting $C$. albicans growth (-static action) and, as an added value, it exhibits a marked anti-collagenase activity which may target fungal virulence in the tissue invasion process.

Table 3 Kinetic parameters on the enzyme inhibition given by the extract of $P$. illyricum

\begin{tabular}{ccc}
\hline & Enzyme with extract & Control \\
\hline $\mathrm{K}_{\mathbf{M}}(\mathrm{mM})$ & 0.189 & 0.372 \\
$\mathrm{~V}_{\max }(\mathrm{nmol} / \mathrm{s})$ & 0.017 & 0.033 \\
\hline
\end{tabular}

\section{Additional files}

Additional file 1: GC-MS chromatogram (TIC on Y-axis) of alkaloid extracts in bulbs of Pancratium illyricum L. Conditions as reported in the text. (A):_galanthamine, $(B)$ : sanguinine, $(C)$ : vittatine, $(D)$ : habranthine, (E): lycorine, (F): leucotamine, (G): O-methylleucotamine, $(\mathrm{H})$ : 2-hydroxyhomolycorine.

Additional file 2: GC-MS of galanthamine in bulb extract of Pancratium illyricum $L$. and relative spectrum from library.

Additional file 3: GC-MS of sanguinine in bulb extract of Pancratium illyricum $L$. and relative spectrum from library.

Additional file 4: GC-MS of vittatine in bulb extract of Pancratium illyricum L. and relative spectrum from library.

Additional file 5: GC-MS of habranthine in bulb extract of Pancratium illyricum $L$. and relative spectrum from library.

Additional file 6: GC-MS of lycorine in bulb extract of Pancratium illyricum L. and relative spectrum from library.

Additional file 7: GC-MS of 2-hydroxyhomolicorine in bulb extract of Pancratium illyricum L. and relative spectrum from library.

\section{Competing interests}

The authors declare that they have no competing interests.

\section{Authors' contributions}

FB designed the work, performed the experiments and analyzed data. FA designed the experiments and wrote the manuscript. $\mathrm{Cl}$ designed the work and performed experiments. AM collected the plant. FP and GAG designed the work. The final manuscript was read and approved by all authors.

\section{Acknowledgments}

This research was supported by Basic Research Program FARB of Ferruccio Poli (Finanziamenti di Ateneo per la Ricerca di Base, 2013) from the University of Bologna.

\section{Author details}

'Department of Pharmacy and Biotechnology, University of Bologna, via Massarenti 9, 40138 Bologna, Italy. Department for Life Quality Studies, University of Bologna, Corso Augusto, 237, 47921 Rimini, Italy. ${ }^{3}$ Department of Pharmacy and Biotechnology, University of Bologna, via Irnerio 42, 40126 Bologna, Italy. ${ }^{4}$ Interacademic Union for Studying of Secondary Metabolites of Vegetal Origin (Co.S.Me.Se.), Viale Ignazio da Laconi 13, Cagliari, Italy. 
Received: 28 June 2014 Accepted: 16 October 2014

Published: 23 October 2014

\section{References}

1. Calderone RA, Fonzi WA: Virulence factors of Candida albicans. Trends Microbiol 2001, 9:327-335.

2. Claveau I, Mostefaoui Y, Rouabhia M: Basement membrane protein and matrix metalloproteinase deregulation in engineered human oral mucosa following infection with Candida albicans. Matrix Biol 2004, 23:477-486.

3. Sterlicht MD, Werb Z: How matrix metalloproteinases regulate cell behavior. Annu Rev Cell Dev Biol 2001, 17:463-516.

4. Nagase $H$, Woessner JF: Matrix metalloproteinases. J Biol Chem 1999, 274:21491-21494

5. Tate P, God J, Bibb R, Lu Q, Larcom LL: Inhibition of metalloproteinase activity by fruit extracts. Cancer Lett 2004, 212:153-158.

6. Kumar MS, Kirubanandan S, Sripriya R, Sengal PK: Triphala promotes healing of infected full-thickness dermal wound. J Sur Res 2008, 144:94-101.

7. Perlin DS: Antifungal drug resistance: do molecular methods provide a way forward? Curr Opin Infect Dis 2009, 22:568-573.

8. Evidente A, Andolfi A, Abou-Donia AH, Touema SM, Hammoda HM, Shawky E, Motta A: (-)-Amarbellisine, a lycorine-type alkaloid from Amaryllis belladonna L. growing in Egypt. Phytochemistry 2004, 65:2113-2118.

9. Casu L, Cottiglia F, Leonti M, De Logu A, Agus E, Tse-Dinh YC, Lombardo V Sissi C: Ungeremine effectively targets mammalian as well as bacterial type I and type II topoisomerases. Bioorg Med Chem Lett 2011, 21:7041-7044.

10. lannello C, Pigni NB, Antognoni F, Poli F, Maxia A, de Andrade JP, Bastida J: A potent acetylcholinesterase inhibitor from Pancratium illyricum $\mathrm{L}$. Fitoterapia 2014, 92:163-167.

11. Adesanya SA, Olugbade TA, Odebiyi OO, Aladesanmi JA: Antibacterial Alkaloids in Crinum jagus. Inter J Pharmacog 1992, 4:303-307.

12. Gundidza M: Screening of extracts from Zimbabwean higher plants: II. Antifungal properties. Fitoterapia 1986, 57:111-114.

13. lannello C, Bastida J, Bonvicini F, Antognoni F, Gentilomi GA, Poli F: Chemical composition, and in vitro antibacterial and antifungal activity of an alkaloid extract from Crinum angustum Steud. Nat Prod Res 2014, 28:704-710.

14. Nkanwen ERS, Gatsing D, Ngamga D, Fodouop SPC, Tane P: Antibacterial agents from the leaves of Crinum purpurascens herb (Amaryllidaceae). Afr Health Sci 2009, 9:264-269.

15. Valsecchi F: Le piante endemiche della Sardegna. Boll Soc Sarda Sci Nat 1982, 21:427-441.

16. Croxatto A, Prod'hom G, Greub G: Applications of MALDI-TOF mass spectrometry in clinical diagnostic microbiology. FEMS Microbiol Rev 2012, 36:380-407.

17. Subcommittee on Antifungal Susceptibility Testing (AFST) of the ESCMID European Committee for Antimicrobial Susceptibility Testing (EUCAST). EUCAST definitive document EDef 7.1: Method for the determination of broth dilution MICs of antifungal agents for fermentative yeasts. Clin Microbiol Infect 2008, 14:398-405.

18. Cantón E, Pemán J, Viudes A, Quindós G, Gobernado M, Espinel-Ingroff A: Minimum fungicidal concentrations of amphotericin B for bloodstream Candida species. Diagn Microbiol Infect Dis 2003, 45:203-206.

19. Thring TSA, Hili P, Naughton DP: Anti-collagenase, anti-elastase and anti-oxidant activities of extracts from 21 plants. BMC Compl Altern Med 2009, 9:27-38

20. Abraham VC, Towne DL, Waring JF, Warrior U, Burns DJ: Application of a high-content multiparameter cytotoxicity assay to prioritize compounds based on toxicity potential in humans. J Biomol Screen 2008, 13:527-537.

21. $\operatorname{Cos} P$, Vlietinck AJ, Berghe DV, Maes L: Anti-infective potential of natural products: how to develop a stronger in vitro 'proof-of-concept'. J Ethnopharm 2006, 106:290-302.

22. Ghosal S, Singh SK, Kumar Y, Unnikrishnan S, Chattopadhyay S: The role of ungeremine in the growth-inhibiting and cytotoxic effects of lycorine: evidence and speculation. Planta Med 1988, 54:114-116.

23. Shen JW, Ruan Y, Ren W, Ma BJ, Wang XL, Zheng CF: Lycorine: a potential broad-spectrum agent against crop pathogenic fungi. J Microbiol Biotechnol 2014, 24:354-358.

24. Imbert C, Kauffmann-Lacroix C, Daniault G, Jacquemin $J$, Rodier MH: Effect of matrix metalloprotease inhibitors on the $95 \mathrm{kDa}$ metallopeptidase of Candida albicans. J Antimicrob Chemother 2002, 49:1007-1010.
25. dos Santos AL, de Carvalho IM, da Silva BA, Portela MB, Alviano CS, de Araújo Soares RM: Secretion of serine peptidase by a clinical strain of Candida albicans: influence of growth conditions and cleavage of human serum proteins and extracellular matrix components. FEMS Immunol Med Microbiol 2006, 46:209-220.

26. Pärnänen $\mathrm{P}$, Kari $\mathrm{K}$, Virtanen I, Sorsa $\mathrm{T}$, Meurman JH: Human laminin-332 degradation by Candida proteinases. J Oral Pathol Med 2008, 37:329-335.

27. Trengove NJ, Stacey MC, MacAuley S, Bennett N, Gibson J, Burslem F, Murphy G, Schultz G: Analysis of the acute and chronic wound environments: the role of proteases and their inhibitors. Wound Repair Regen 1999, 7:442-452.

28. Arias ME, Gomez JD, Cudmani NM, Vattuone MA, Isla Ml: Antibacterial activity of ethanolic and aqueous extracts of Acacia aroma Gill. ex Hook et Arn. Life Sci 2004, 75:191-202.

doi:10.1186/1472-6882-14-409

Cite this article as: Bonvicini et al.: Relevant and selective activity of Pancratium illyricum L. against Candida albicans clinical isolates: a combined effect on yeast growth and virulence. BMC Complementary and Alternative Medicine 2014 14:409.

\section{Submit your next manuscript to BioMed Central and take full advantage of:}

- Convenient online submission

- Thorough peer review

- No space constraints or color figure charges

- Immediate publication on acceptance

- Inclusion in PubMed, CAS, Scopus and Google Scholar

- Research which is freely available for redistribution

Submit your manuscript at www.biomedcentral.com/submit
C Biomed Central 